\title{
Summarized Results of the Experimental Determination of Heat Losses Through Fixed Supports of Steam Pipelines
}

\author{
Stefan Kalchev, Petar Kostov, Chavdar Nikolov, Koycho Atanasov* \\ Department of Mechanics Machine Building and Heat Engineering, Faculty of Engineering and Pedagogy - Sliven, Technical University of \\ Sofia, Sliven, Bulgaria
}

\section{Email address:}

skalchevbg@abv.bg (S. Kalchev), PStKostov@tu-sliven.com (P. Kostov), nikolov.chavdar@abv.bg (C. Nikolov), koycho_atanasov@abv.bg (K. Atanasov)

${ }^{*}$ Corresponding author

\section{To cite this article:}

Stefan Kalchev, Petar Kostov, Chavdar Nikolov, Koycho Atanasov. Summarized Results of the Experimental Determination of Heat Losses Through Fixed Supports of Steam Pipelines. International Journal of Economics, Finance and Management Sciences.

Vol. 5, No. 6, 2017, pp. 294-299. doi: 10.11648/j.ijefm.20170506.13

Received: September 12, 2017; Accepted: October 6, 2017; Published: November 16, 2017

\begin{abstract}
The results of the experimental determination of the heat losses in fixed supports of low, medium and high pressure steam pipelines in firm Lukoil Neftochim Burgas have been summarized. In the conditions of a three-factor experiment, the exponents of the regression equation have been determined. For determination of convective heat exchange coefficient $(\alpha)$, the Newton-Rihmann equation has been used as a boundary condition of a third kind of heat transfer equation. Experimentally obtained $\alpha$ dependency has been shown as a function of the dimensionless temperature and the velocity and angle of the airflow of support. The results obtained shall be considered as part of the effort to structure user-friendly software for heat losses determination of steam pipelines and their components by means of thermal imaging equipment.
\end{abstract}

Keywords: Heat Losses, Steam Pipelines, Fixed Supports, Dimensional Analysis, Criterion Equation

\section{Introduction}

The two previous publications [1,2] have shown the possibilities for heat losses determination using a thermal imaging camera. Therefore the method for real time heat losses determination from heat transfer pipelines through specialized software based on determination of the heat flow which has passed from the insulated surface of the pipeline, fittings and fixed supports to the environment seems promising, providing a reason to continue the researches in this direction until the successful validation or rejection of the method. In this regard there are significant difficulties to find a mathematical relationship for determination of losses in fixed supports convenient for engineering use. Based on dimensional analysis [3] an exponential function has been proposed of dimensionless criteria of a similarity of the kind

$$
\frac{Q}{C}=\left(\frac{\lambda}{\alpha \cdot \delta}\right)^{b} \cdot\left(\frac{F}{\delta^{2}}\right)^{d} \cdot\left(\frac{t_{o}}{\Delta t}\right)^{e}
$$

where: $\left(\frac{\lambda}{\alpha \cdot \delta}\right)=\frac{1}{B i}$ is the reciprocal value of Biot criterion,

$\left(\frac{t_{o}}{\Delta t}\right)$ is the dimensionless temperature, and

$\left(\frac{F}{\delta^{2}}\right)$ is the dimensionless geometric criterion.

The complexes of magnitudes in equation (1) contain the main factors influencing the heat released by the support and have a definite physical meaning [4]. The left part of the equation takes a dimensionless form by grouping the physical magnitudes with an exponent one in the auxiliary function $\mathrm{c}$ $=\alpha \cdot \delta^{2} \cdot \Delta \mathrm{t}$ with dimensionality $[\mathrm{W}]$.

\section{Subject Characteristics}

The subject of the study is a typical fixed support used in the steam network of Lukoil Neftochim Burgas, used in steam pipelines with DN 300 - DN 600. A laboratory model 
has been constructed in the Faculty of Engineering and Pedagogy - Sliven of Technical University of Sofia for experimental determination of the losses in the supports. The mechanical structure and electrical diagram of the model have been presented in [1]. Upon maximum approximation of the insulation to the adiabatic conditions and stationary heat transfer mode, the heat input through the electric heaters is equal to the heat flow passing in the support.

\section{Purpose}

The purpose is the development of a reliable mathematical model that can be used for the structuring of a suitable software product that allows the real time determination of heat losses in the supports. From the stated purpose comes the task, based on the experiment carried out, to determine the exponents of the regression equation (1).

\section{Method of the Study}

It concerns the performance of a thermal engineering experiment with orthogonal planning of first order. Several scientifically-based methods are known for experiment data processing. The most widely spread and frequently used is the least squares method. This method, as known [5], is based on the equation

$$
\mathrm{SUM}=\sum_{1}^{n}\left(\bar{y}_{i}-y_{i}\right)=\min
$$

where: $\bar{y}_{i}$ is the arithmetic mean of the magnitude sought, and $y_{i}$ is its value in compliance with the mathematical model. Equation (1) is used as physical model. For determination of convective heat exchange coefficient $\alpha$ $\left[\mathrm{W} /\left(\mathrm{m}^{2} . \mathrm{K}\right)\right]$ the experimentally obtained results are used according to Newton-Richmann's law:

$$
\mathrm{Q}=\alpha . \mathrm{F} .\left(\mathrm{t}_{\mathrm{W}}-\mathrm{t}_{\mathrm{oc}}\right)
$$

where: $Q[\mathrm{~W}]$ is the experimentally determined thermal power, $F\left[\mathrm{~m}^{2}\right]$ is the area of the support, $t_{W}\left[{ }^{\circ} \mathrm{C}\right]$ is the measured with thermal imaging camera integral temperature of support, and $t_{o c}\left[{ }^{\circ} \mathrm{C}\right]$ is the ambient temperature. Strictly speaking, the presence of the three criteria of similarity in equation (1) determines the performance of a three-factor experiment, that is to say, the solutions shall be located in the factorial space of a volumetric geometric figure, but since the support of the experiments has a fixed surface and thickness, the dimensionless geometric criterion $\left(\frac{F}{\delta^{2}}\right)$ has a specific value $\left(\frac{0,221}{0,002^{2}}\right)=55250$, which transforms the experiment into a two-factor one and the equation of regression (1) takes the following form:

$$
\frac{\mathrm{Q}}{\mathrm{C}}=(55250)^{\mathrm{d}} \cdot\left(\frac{\lambda}{\alpha \cdot \delta}\right)^{b} \cdot\left(\frac{t_{o}}{\Delta t}\right)^{e}
$$

It is known [6], that the solutions of this kind are located in a planar geometric figure, whose shape and magnitude depend on the range of function argument variations. As far as one plane is defined by three points, the task is to solve a system of three equations in logarithmic coordinates.

$$
\ln \left(\frac{\mathrm{Q}}{\mathrm{C}}\right)=d \cdot \ln (55250)+b \cdot \ln \left(\frac{\lambda}{\alpha \cdot \delta}\right)+e \cdot \ln \left(\frac{t_{o}}{\Delta t}\right)
$$

It is convenient to apply the substitution:

$$
y=\ln \left(\frac{Q}{\alpha \cdot \delta^{2} . \Delta t}\right), x_{1}=\ln \left(\frac{\lambda}{\alpha \cdot \delta}\right), x_{2}=\ln \left(\frac{t_{o}}{\Delta t}\right)
$$

Due to the fact that the unknowns in the equation are three, the task is to solve the system:

$$
\begin{aligned}
& y_{1}=d \cdot 10,92+b \cdot x_{11}+e \cdot x_{21} \\
& y_{2}=d \cdot 10,92+b \cdot x_{12}+e \cdot x_{22} \\
& y_{3}=d \cdot 10,92+b \cdot x_{13}+e \cdot x_{23}
\end{aligned}
$$

where: $\boldsymbol{y}_{i}, \boldsymbol{x}_{1 i}$, and $\boldsymbol{x}_{2 i}$ are the determined based on equation (3) experimentally averaged values of dimensionless complexes, while $d, b$ and $\boldsymbol{e}$ are the unknown exponents. The three equations are obtained like the based ones on the plan of the experiment. The accuracy of the algebraic method depends whether one of the selected equations will pass through the center of the two-factor space, which in the logarithmic coordinates has an orthogonal geometric interpretation. As an alternative to the purely algebraic method in more complex multifactor experiments, it is possible to apply the orthogonal planning method using normalized factors [5].

The reproducibility of the results and the adequacy of the mathematical model shall be verified by a statistical check known as regression analysis. These models shall be considered to be adequate in which the uniformity of the reproducibility dispersion and the adequacy dispersion is observed. [4] The hypothesis of dispersion persistence of the experimentally determined results shall be confirmed by the Cochrane's G-criterion and the adequacy of the mathematical model is verified by Fisher's F-criterion. In an exponential function of the type of equation (5), the exponents are of high significance and it is not required to make an evaluation according to the t- criterion of Student [5].

\section{Results and Analysis}

Upon fixed values of support thickness $\delta=0,002[\mathrm{~m}]$, the area of the uninsulated part $\mathrm{F}=0,221\left[\mathrm{~m}^{2}\right]$, and the heat transfer coefficient of the metal $\lambda=52[\mathrm{~W} /(\mathrm{m} . \mathrm{K})]$, the independent variables are the convective heat transfer coefficient $\alpha$ (as a function of airflow velocity) and temperature difference between the integral temperature of support surface and the environment $\Delta t$. The experimental model allows based on the boundary condition of a third kind [6] of heat transfer equation to determine empirically the 
dependence $\alpha=f(v)$ within a range of natural convection at $v$ $=0 \mathrm{~m} / \mathrm{s}$ to a pronounced turbulent flow with $v=10 \mathrm{~m} / \mathrm{s}$. Three characteristic modes have been used for $t_{0}=183,205$ and $241\left[{ }^{\circ} \mathrm{C}\right]$, corresponding to the steam saturation temperature in low, medium and high pressure steam pipelines of 1, 1,5 and $2[\mathrm{MPa}]$ respectively. These temperatures remain constant throughout the experiment. The consumed electrical power of heaters is measured $(Q)$ as well as the temperature difference between the temperature of the uninsulated surface of the support $\left(t_{w}\right)$ and the ambient temperature $\left(\boldsymbol{t}_{\boldsymbol{o c}}\right)$ under different velocities and angles of airflow. The results in graphical form are shown in figure 1 to figure 3 . The obtained dependencies are approximated as an exponential function.

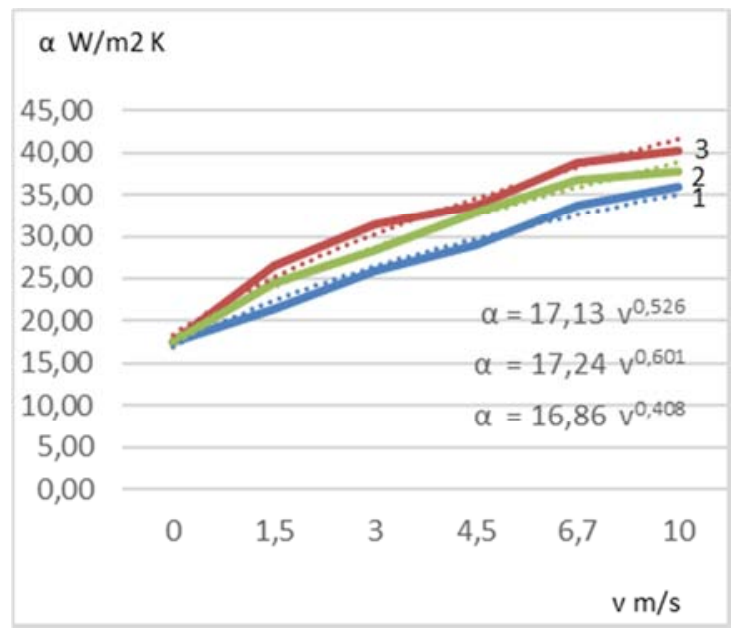

Figure 1. $\alpha=f(v)$ at $t_{o}=183^{\circ} \mathrm{C}(1-\pi / 2 \mathrm{rad}, 2-\pi / 3 \mathrm{rad}, 3-\pi / 6 \mathrm{rad})$.

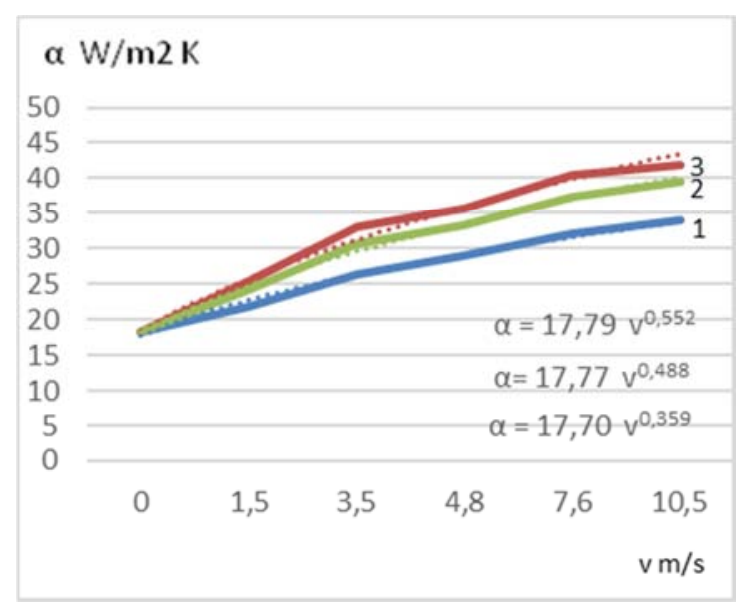

Figure 2. $\alpha=f(v)$ at $t_{o}=205^{\circ} \mathrm{C}(1-\pi / 2 \mathrm{rad}, 2-\pi / 3 \mathrm{rad}, 3-\pi / 6 \mathrm{rad})$.

To summarize the results of the experiment, the method of orthogonal planning using normalized factors is applied. The matrix of the experimental plan is determined by the endpoints of the factor space. The range of change of the values of the independent variables and the limit values of the heat losses are shown in Table 1.

The range of change of similarity criteria, participating in the experiment is shown in Table 2.

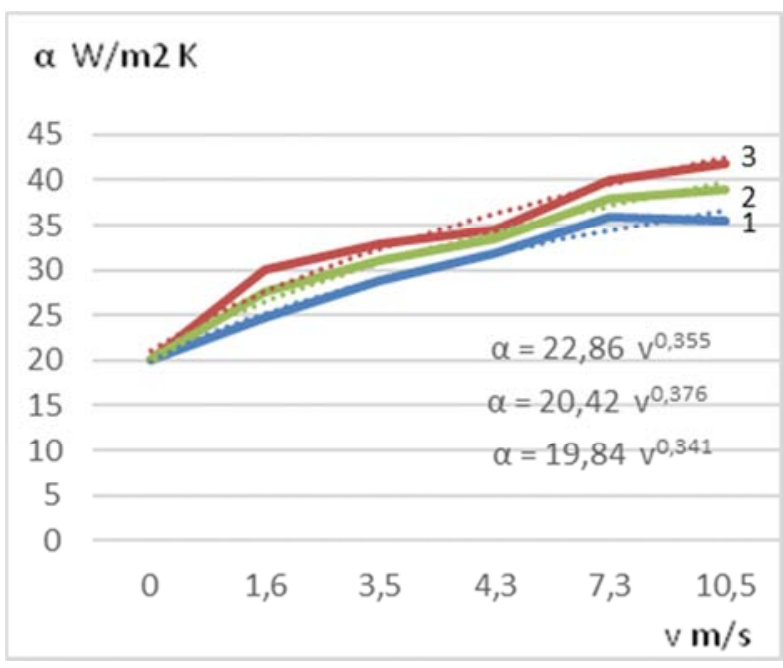

Figure 3. $\alpha=f(v)$ at $t_{o}=241^{\circ} \mathrm{C}(1-\pi / 2 \mathrm{rad}, 2-\pi / 3 \mathrm{rad}, 3-\pi / 6 \mathrm{rad})$.

The normalization procedure essentially consists in the fact that having the maximum and minimum logarithmic meanings of both factors $\left(\mathrm{x}_{\max }\right.$ and $\left.\mathrm{x}_{\min }\right)$ one of the mean $\mathrm{x}_{\mathrm{o}}$ for each of both factors is determined. These "zero" values of $\mathrm{x}_{1}$ and $\mathrm{x}_{2}$ as per [5] determine the coordinates of the central point of the plan through which one of the equations of the system passes (6):

$$
\begin{aligned}
& x_{1,0}=\frac{x_{1 \min }+x_{1 \max }}{2}=\frac{6,428+7,275}{2}=6,852 \\
& x_{2,0}=\frac{x_{2 \min }+x_{2 \max }}{2}=\frac{1,297+2,489}{2}=1,893
\end{aligned}
$$

The range of deviations is the difference between the maximum and minimum logarithmic meanings of both factors:

$$
\begin{gathered}
\Delta x_{1}=\frac{x_{1 \max }-x_{1 \min }}{2}=\frac{7,275-6,428}{2}=0,424 \\
\Delta x_{2}=\frac{x_{2 \max }-x_{2 \min }}{2}=\frac{2,489-1,297}{2}=0,596
\end{gathered}
$$

The graphic interpretation of the factor space is shown in Figure 4. 


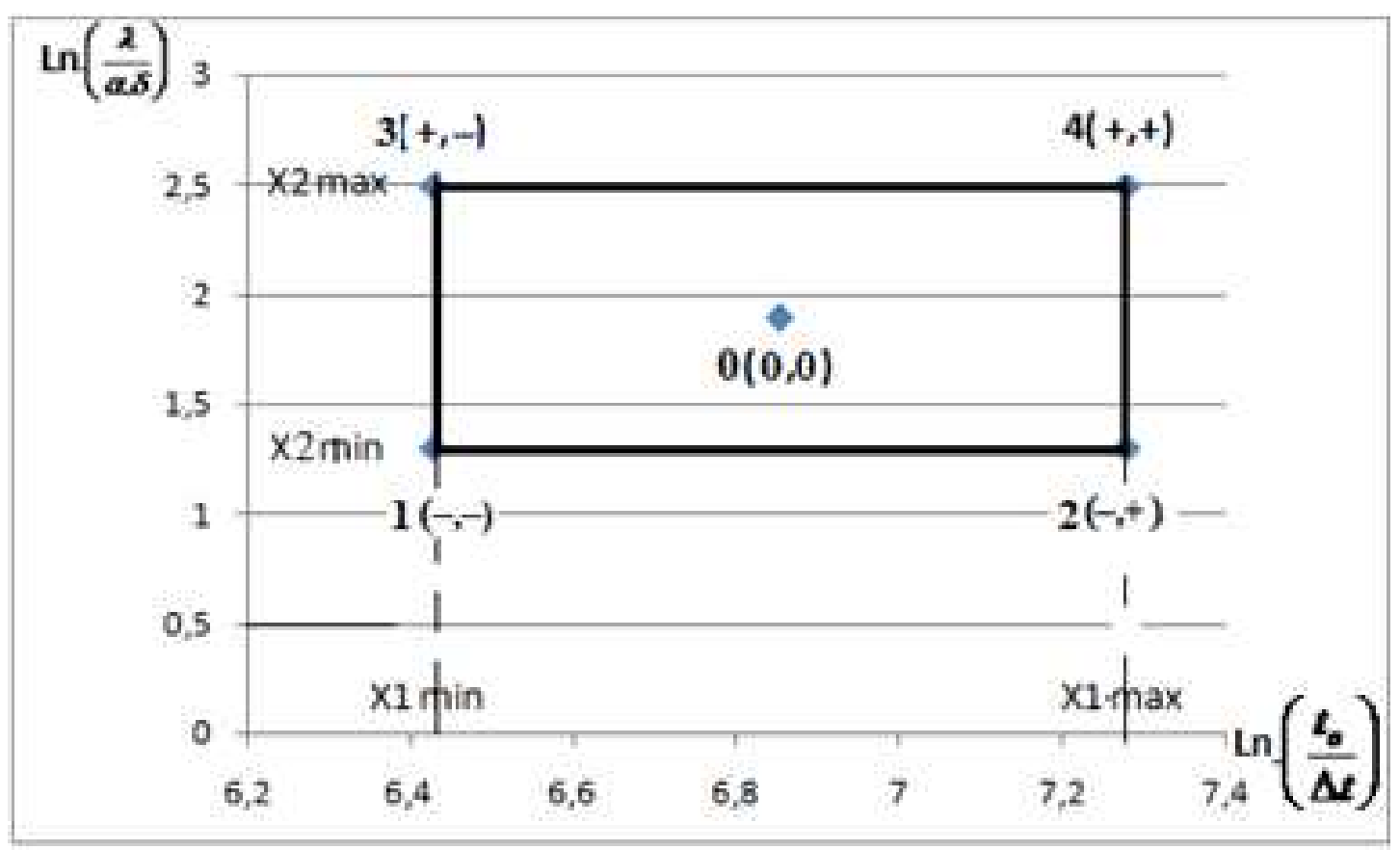

Figure 4. Graphic Form of the Area of Solutions in Logarithmic Coordinates.

Table 1. Range of Change of Values of Independent Variables.

\begin{tabular}{|c|c|c|c|c|}
\hline Temperature levels & $183^{\circ} \mathrm{C}$ & $205^{\circ} \mathrm{C}$ & $241^{\circ} \mathrm{C}$ & Range \\
\hline$\alpha_{\min ,}\left[\mathrm{W} /\left(\mathrm{m}^{2} . \mathrm{K}\right)\right]$ & 17,6 & 18,0 & 18,2 & 18,0 \\
\hline$\alpha_{\max },\left[\mathrm{W} /\left(\mathrm{m}^{2} . \mathrm{K}\right)\right]$ & 40,2 & 40,8 & 41,9 & 42,0 \\
\hline$\Delta \mathrm{t}_{\min },\left[{ }^{\circ} \mathrm{C}\right]$ & 19,9 & 21,6 & 23,5 & 20 \\
\hline$\Delta \mathrm{t}_{\max ,}\left[{ }^{\circ} \mathrm{C}\right]$ & 39,8 & 45,2 & 49,7 & 50 \\
\hline $\mathrm{Q}_{\min ,}[\mathrm{W}]$ & 77,4 & 85,9 & 94,5 & 80 \\
\hline $\mathrm{Q}_{\max ,}[\mathrm{W}]$ & 353,6 & 407,5 & 460,2 & 464 \\
\hline
\end{tabular}

Table 2. Range of Change of Similarity Criteria, Participating in the Experiment.

\begin{tabular}{|c|c|c|c|c|c|c|c|c|c|c|c|}
\hline \multirow[b]{2}{*}{ Criteria } & \multirow[b]{2}{*}{ Factor } & \multirow[b]{2}{*}{ Level } & \multicolumn{7}{|c|}{ Numerical meanings of parameters } & \multicolumn{2}{|l|}{ Meaning } \\
\hline & & & $\delta[\mathbf{m}]$ & $\mathbf{F}\left[\mathbf{m}^{2}\right]$ & $\begin{array}{l}\mathbf{t}_{\mathbf{o}} \\
\left.{ }^{\circ} \mathrm{C}\right]\end{array}$ & $\begin{array}{l}\Delta \mathbf{t} \\
{\left[{ }^{\circ} \mathrm{C}\right]}\end{array}$ & $\lambda[\mathbf{W} /(\mathbf{m} . \mathbf{K})]$ & $\mathbf{v}[\mathbf{m} / \mathbf{s}]$ & $\alpha\left[\mathbf{W} /\left(\mathbf{m}^{2} \cdot \mathbf{K}\right)\right]$ & Criterion & In \\
\hline$(F)$ & \multirow[b]{2}{*}{ Const. } & Upper & 0,002 & 0,221 & & & & & & 55250 & 10,92 \\
\hline$\left(\frac{1}{\delta^{2}}\right)$ & & Lower & 0,002 & 0,221 & & & & & & 55250 & 10,92 \\
\hline$(\lambda)$ & \multirow[b]{2}{*}{$x_{1}$} & Upper & & & & & 52 & 0 & 18 & 1444 & 7,275 \\
\hline$(\overline{\alpha . \delta})$ & & Lower & & & & & 52 & 10 & 42 & 619 & 6,428 \\
\hline$\left(t_{o}\right)$ & \multirow[b]{2}{*}{$x_{2}$} & Upper & & & 241 & 20 & & & & 12,05 & 2,489 \\
\hline$\left(\frac{o_{0}}{\Delta t}\right)$ & & Lower & & & 183 & 50 & & & & 3,66 & 1,297 \\
\hline
\end{tabular}

Under these boundary conditions, experiments were carried out for each separate point to determine the heat load. Thus, the condition for the least square deviation is observed, as they are equidistant from the central point. The results are shown in Table 3.

From the theory of the experiment $[4,5]$ it is known that in the simultaneous execution of the four boundary conditions, the coefficients of regression of the mathematical model in logarithmic coordinates are easily found in the following formulas in which $\mathrm{N}$ is the number of experiments, in this case 4.

$$
B^{*}=\frac{1}{N} \sum_{1}^{N} \overline{y_{12}} \mathrm{X}_{1}^{*}=\frac{1}{4} 0,188=0,0470
$$

$$
\begin{gathered}
E^{*}=\frac{1}{N} \sum_{1}^{N} \overline{y_{12}} \mathrm{X}_{2}^{*}=\frac{1}{4} 0,190=0,0475 \\
D^{*}=\frac{1}{N} \sum_{1}^{N} \overline{y_{12}}=\frac{1}{4} 43,65=10,912
\end{gathered}
$$

The regression equation in logarithmic coordinates takes the following form:

$$
y=D^{*}+B^{*} \mathrm{X}_{1}^{*}+E^{*} \mathrm{X}_{2}^{*}
$$

By the reverse transformation are obtained the regression coefficients of logarithmic equation (5). 
Table 3. Results of the Experiments in Natural and Logarithmic. Expression at the Bounder Points of the Factor Space.

\begin{tabular}{|c|c|c|c|c|c|c|c|c|c|c|c|}
\hline \multirow[b]{2}{*}{ № } & \multicolumn{2}{|c|}{$\begin{array}{l}\text { Meaning of } \\
\text { criteria }\end{array}$} & \multicolumn{3}{|c|}{ Experiment results } & \multicolumn{6}{|c|}{ Auxiliary logarithmic functions } \\
\hline & $\left(\frac{\lambda}{\alpha \cdot \delta}\right)$ & $\left(\frac{t_{o}}{\Delta t}\right)$ & $\left(\frac{Q}{\alpha \cdot \delta^{2} \cdot \Delta \mathrm{t}}\right) 183^{\circ} \mathrm{C}$ & $\left(\frac{Q}{\alpha \cdot \delta^{2} \cdot \Delta \mathrm{t}}\right) \mathbf{2 0 5}^{\circ} \mathrm{C}$ & $\left(\frac{Q}{\alpha \cdot \delta^{2} \cdot \Delta \mathrm{t}}\right) 241^{\circ} \mathrm{C}$ & $\sum^{3}\left(\frac{Q}{\alpha \cdot \delta^{2} \cdot \Delta \mathrm{t}}\right)$ & $\overline{\mathrm{y}_{12}}$ & $\mathbf{X} 1^{*}$ & $\mathbf{X} 2 *$ & $\overline{y_{12}} \mathbf{X} 1 *$ & $\overline{\mathrm{y}_{12}} \times 2$; \\
\hline 1 & 619 & 3,66 & 42214 & 48523 & 54762 & 49499 & 10,810 & -1 & -1 & $-10,810$ & $-10,810$ \\
\hline 2 & 1444 & 3,66 & 55319 & 55310 & 55277 & 55302 & 10,920 & +1 & -1 & $-10,920$ & $-10,920$ \\
\hline 3 & 619 & 12,05 & 55314 & 55317 & 55350 & 55327 & 10,921 & -1 & +1 & 10,921 & 10,921 \\
\hline 4 & 1444 & 12,05 & 53700 & 59722 & 65972 & 59815 & 10,999 & +1 & +1 & 10,999 & 10,999 \\
\hline$\Sigma$ & 0 & 0 & & & & & 43,65 & 0 & 0 & 0,188 & 0,190 \\
\hline \multicolumn{12}{|c|}{ Results at the central point of the plan } \\
\hline 0 & 1031,5 & 7,855 & 51637 & 54718 & 57840 & 54986 & 10,912 & & & 0,0470 & 0,0475 \\
\hline
\end{tabular}

$$
\begin{gathered}
b=\frac{B^{*}}{\Delta x_{1}}=\frac{0,0470}{0,424}=0,1108 \\
e=\frac{E^{*}}{\Delta x_{2}}=\frac{0,0475}{0,596}=0,0797 \\
d=\frac{D^{*} \cdot\left(b \cdot x_{1,0}+e \cdot x_{2,0}\right)}{D^{*}}=\frac{10,912 \cdot(0,1108 \cdot 6,852+0,0797 \cdot 1,893)}{10,912}=0,9167
\end{gathered}
$$

Since the regression coefficients are the exponents of the natural equation (4), the mathematical model by which heat losses through a specific support can be determined takes the following form:

$$
\frac{Q}{\alpha \cdot \delta^{2} . \Delta t}=(55250)^{0,9167} \cdot\left(\frac{\lambda}{\alpha . \delta}\right)^{0,1108} \cdot\left(\frac{t_{o}}{\Delta t}\right)^{0,0797}
$$

The main regression analysis procedures are the assessment of the magnitude of the regression coefficients and the verification of the adequacy hypothesis. In this case, verification of the relevance of the coefficients is not necessary because their effect is immediate. It is obvious, the results in the combination $(+-)$ and $(-+)$ are very close and they actually coincide with the center of factor space. This is because the two factors influencing heat exchange with the environment have mutually opposite effects. With increasing airflow rate, the factor $\mathrm{x} 1$ (the reciprocal value of the criterion of Bio) is growing and $x_{2}$ (dimensionless temperature) reduces and to a great extent the two effects compensate each other. These mathematical models shall be considered adequate where the condition for uniformity of both dispersions is observed - the reproducibility dispersion:

$$
S_{(y)}^{2}=\frac{\sum_{1}^{N} n(\bar{Q}-\hat{Q})^{2}}{N-L}
$$

and the adequacy dispersion

$$
S_{(a d)}^{2}=\frac{\sum_{1}^{n}\left(Q_{i j}-\bar{Q}\right)^{2}}{n-1}
$$

where:

$\mathrm{L}$ is the quantity of significant coefficients (in this case 2);

$\bar{Q}_{i}$ is the mean arithmetic meaning of the result for each ith point, limiting the area of solutions;

$\hat{Q}_{i}$ is the estimated value, determined by the mathematical model;

$\mathrm{N}$ is the number of the points in the factor space, where experiments have been performed (in this case 4);

$\mathrm{n}$ is the number of parallel experiments in each $\mathrm{i}$-th point (in this case 3 ).

Comparison of a representative sample of the experimental results with the predictions determined by the mathematical model (19) are presented in Table 4.

For verification of uniformity hypothesis an assessment has been made through G- criterion of Cochrane and Fcriterion of Ficher

$$
G=\frac{s_{(y) i \cdot \max }^{2}}{\sum_{1}^{n} s_{(y) i}^{2}}=\frac{27,477}{80,448}=0,304 \leq G_{t a b l}=0,7457
$$

\begin{tabular}{|c|c|c|c|c|c|c|c|c|c|c|c|c|c|c|c|}
\hline \multirow{3}{*}{ № } & \multicolumn{8}{|c|}{ Results } & \multirow{3}{*}{$\begin{array}{l}\text { Prediction } \\
\hat{Q}[\mathrm{~W}]\end{array}$} & \multicolumn{6}{|c|}{ Data for dispersion determination } \\
\hline & \multirow{2}{*}{$\begin{array}{l}\mathbf{v} \\
{\left[\frac{\mathbf{m}}{\mathbf{s}}\right]}\end{array}$} & \multirow{2}{*}{$\begin{array}{l}\alpha \\
{\left[\frac{\mathrm{W}}{\mathrm{m}^{2} \cdot \mathrm{K}}\right]}\end{array}$} & \multirow[t]{2}{*}{$\begin{array}{l}\mathbf{t}_{\mathbf{o}} \\
{\left[{ }^{\circ} \mathbf{C}\right]}\end{array}$} & \multirow{2}{*}{$\begin{array}{l}\Delta \mathbf{t} \\
{\left[{ }^{\circ} \mathbf{C}\right]}\end{array}$} & \multirow[t]{2}{*}{$\begin{array}{l}\mathbf{Q}_{\mathrm{i1}} \\
{[\mathbf{W}]}\end{array}$} & \multirow[t]{2}{*}{$\begin{array}{l}\mathbf{Q}_{\mathrm{i} 2} \\
{[\mathrm{~W}]}\end{array}$} & \multirow[t]{2}{*}{$\begin{array}{l}\mathbf{Q}_{\mathrm{i3}} \\
{[\mathbf{W}]}\end{array}$} & \multirow{2}{*}{$\begin{array}{c}\bar{Q}_{i} \\
{[\mathbf{W}]}\end{array}$} & & \multirow[t]{2}{*}{$\begin{array}{l}\text { Adeq. } \\
\left(\bar{Q}_{i}-\hat{Q}_{i}\right)^{2}\end{array}$} & \multirow[t]{2}{*}{$\begin{array}{l}\text { Disp. } \\
\mathrm{S}_{(\text {(ad) }}^{2}\end{array}$} & \multicolumn{3}{|c|}{$\begin{array}{l}\text { Reproducib. } \\
\left(Q_{Q_{i j}}-\bar{Q}_{i}\right)^{2}\end{array}$} & \multirow[t]{2}{*}{$\begin{array}{l}\text { Disp. } \\
S_{(y)}^{2}\end{array}$} \\
\hline & & & & & & & & & & & & $\mathrm{J}=1$ & $\mathrm{~J}=2$ & $\mathrm{~J}=3$ & \\
\hline 1 & 0,00 & 17,6 & 183 & 38,6 & 148 & 153 & 149 & 150,0 & 152,79 & 7,7841 & 11,676 & 4,00 & 9,00 & 1,00 & 7,00 \\
\hline 2 & 1,50 & 21,3 & 183 & 26,9 & 162 & 163 & 163 & 162,7 & 162,85 & 0,0225 & 0,034 & 0,49 & 0,09 & 0,09 & 0,67 \\
\hline 3 & 4,60 & 37,7 & 184 & 20,9 & 172 & 177 & 174 & 174,3 & 171,79 & 6,3001 & 9,450 & 5,29 & 7,29 & 0,09 & 12,67 \\
\hline 4 & 10,6 & 51,7 & 183 & 15,4 & 177 & 178 & 176 & 177,0 & 174,74 & 5,1076 & 7,661 & 0,00 & 1,00 & 1,00 & 2,00 \\
\hline 5 & 0,00 & 20,0 & 206 & 40,7 & 180 & 182 & 179 & 180,3 & 181,86 & 2,4336 & 2,434 & 0,09 & 1,69 & 18,5 & 20,27 \\
\hline
\end{tabular}

where: $s_{(y) \text { imax }}^{2}$ is the maximum recorded value of the mean square deviation (line 9, table 4 ) and $G_{\text {tabl }}$ is the table value of the criterion at confidence interval 0,95 [5].

Table 4. Regression Analysis Data. 


\begin{tabular}{|c|c|c|c|c|c|c|c|c|c|c|c|c|c|c|c|}
\hline \multirow{3}{*}{ № } & \multicolumn{8}{|c|}{ Results } & \multirow{3}{*}{$\begin{array}{l}\text { Prediction } \\
\hat{Q}[\mathrm{~W}]\end{array}$} & \multicolumn{6}{|c|}{ Data for dispersion determination } \\
\hline & \multirow{2}{*}{$\begin{array}{l}\mathbf{v} \\
{\left[\frac{\mathbf{m}}{\mathbf{s}}\right]}\end{array}$} & \multirow{2}{*}{$\stackrel{\alpha}{\left[\frac{W}{m^{2} \cdot K}\right]}$} & \multirow[t]{2}{*}{$\begin{array}{l}\mathbf{t}_{0} \\
{\left[{ }^{\circ} \mathbf{C}\right]}\end{array}$} & \multirow[t]{2}{*}{$\begin{array}{l}\Delta \mathbf{t} \\
{\left[{ }^{\circ} \mathbf{C}\right]}\end{array}$} & \multirow[t]{2}{*}{$\begin{array}{l}\mathbf{Q}_{\mathrm{i1}} \\
{[\mathbf{W}]}\end{array}$} & \multirow[t]{2}{*}{$\begin{array}{l}\mathbf{Q}_{\mathrm{i} 2} \\
{[\mathbf{W}]}\end{array}$} & \multirow[t]{2}{*}{$\begin{array}{l}\mathbf{Q}_{\mathrm{i} 3} \\
{[\mathrm{~W}]}\end{array}$} & \multirow{2}{*}{$\begin{array}{c}\overline{\boldsymbol{Q}}_{i} \\
{[\mathbf{W}]}\end{array}$} & & \multirow[t]{2}{*}{$\begin{array}{l}\text { Adeq. } \\
\left(\bar{Q}_{i}-\hat{Q}_{i}\right)^{2}\end{array}$} & \multirow[t]{2}{*}{$\begin{array}{l}\text { Disp. } \\
\mathrm{S}_{(\text {(ad) }}^{2}\end{array}$} & \multicolumn{2}{|c|}{$\begin{array}{l}\text { Reproducib. } \\
\left(Q_{i j}-\bar{Q}_{i}\right)^{2}\end{array}$} & & \multirow[t]{2}{*}{$\begin{array}{l}\text { Disp. } \\
S_{(y)}^{2}\end{array}$} \\
\hline & & & & & & & & & & & & $\mathrm{J}=1$ & $\mathrm{~J}=2$ & $\mathrm{~J}=3$ & \\
\hline 6 & 1,60 & 24,7 & 205 & 33,3 & 181 & 183 & 182 & 182,0 & 183,19 & 1,4161 & 2,124 & 1,00 & 1,00 & 1,00 & 3,00 \\
\hline 7 & 4,30 & 31,9 & 206 & 26,6 & 186 & 188 & 188 & 187,3 & 186,35 & 0,9025 & 0,947 & 1,69 & 0,49 & 0,49 & 2,67 \\
\hline 8 & 10,4 & 41,9 & 205 & 21,1 & 195 & 193 & 196 & 194,7 & 191,99 & 7,3441 & 11,016 & 0,09 & 2,89 & 1,69 & 4,67 \\
\hline 9 & 0,00 & 18,2 & 241 & 40,8 & 200 & 203 & 197 & 200,0 & 204,28 & 18,318 & 27,477 & 0,00 & 9,00 & 9,00 & 18,00 \\
\hline 10 & 1,50 & 25,2 & 241 & 26,2 & 206 & 205 & 201 & 204 & 205,85 & 3,4225 & 5,134 & 4,00 & 1,00 & 9,00 & 14,00 \\
\hline 11 & 4,80 & 28,9 & 242 & 32,4 & 208 & 207 & 205 & 206,7 & 207,88 & 1,3924 & 2,089 & 1,69 & 0,09 & 2,89 & 4,67 \\
\hline 12 & 10,5 & 33,9 & 241 & 28,1 & 210 & 213 & 211 & 211,3 & 210,48 & 0,2704 & 0,406 & 1,69 & 2,89 & 0,09 & 4,67 \\
\hline
\end{tabular}

$$
F=\frac{s_{(a d)}^{2}}{s_{(y) i}^{2}}=\frac{80,448}{94,290}=0,853 \leq F_{t a b l}=4,46
$$

where $F_{\text {tabl }}$ is the table value of the criterion at confidence interval 0,95 .

Adding the geometric criterion of similarity $\left(\frac{F}{\delta^{2}}\right)$ at the place of the constant 55250 under the same exponents transforms equation (1) in:

$$
\frac{Q}{\alpha \cdot \delta^{2} \cdot \Delta t}=\left(\frac{F}{\delta^{2}}\right)^{0,9167} \cdot\left(\frac{\lambda}{\alpha \cdot \delta}\right)^{0,1108}\left(\frac{t_{o}}{\Delta t}\right)^{0,07977}
$$

With great credibility it can be assumed that in this kind the solutions of equation (21) will be satisfactory for any and with different configuration of supports but in order to use it as a universal mathematical model for estimating the heat losses through fixed supports, this assumption shall be proven experimentally.

\section{Conclusions}

1. Based on experiments performed, functional dependence was found $\alpha=f(v)$ at $t_{o}=$ const. The approximation of the experimental curves in exponential function allows the analytical determination of $\alpha$ for a given temperature regime at a certain wind velocity and direction.

2. Through the method of orthogonal planning, using normalized factors, the results of the experiment were analysed and the exponents of criterion equation proposed as mathematical model have been determined.

3. The equation is $95 \%$ credible that Cochrane and Fisher criteria for reproducibility and adequacy can be used as a mathematical model for determining heat losses through fixed supports as part of the larger scale task of producing engineering applicable software to determine aggregate heat losses of steam pipelines at Lukoil Neftochim Burgas site by measuring their surface temperature using thermal imaging equipment.

\section{References}

[1] P. Kostov, Ch. I. Nikolov, K. T. Atanasov, S. V. Kalchev, Heat losses determination in supports by means of thermal imaging camera, Technical University Sofia, Thermal Power Engineering Faculty, XIX International Scientific Conference, Collection of Papers, Volume I, 2014, pp. 186-190.

[2] P. Kostov, Ch. I. Nikolov, K. T. Atanasov, S. V. Kalchev, Dependencies in heat losses determination in fixed supports of heat transfer pipelines using thermal imaging camera, Scientific papers RU-2024, volume 53, series 1.2 pp. 57-61.

[3] H. Huntly, Dimensional analysis, New York: Dover Publ. Inc. 1967.

[4] V. Osipova Experimental study of heat transfer processes, Moscow: Energy, 1979.

[5] B. Semenov, Engineering experiment in industrial thermal engineering, Saratov: Heat and heat engineering, 2009.

[6] P. Isachenko, V. A. Osipova, A. S. Sukomel, Heat transfer, Moscow, Energy, 1975.

[7] D. Montgomery, Design and Analysis of Experiments; Wiley, 2001.

[8] F. Kreith, W. Black, Basic Heat Transfer, New York: Harper and Row Publishers, 1980.

[9] M. Hossain, Heat and Mass Transfer - Modeling and Simulation, Publisher: In Tech, 2011.

[10] S. Sendov, Heat and mass transfer, Sofia: Tehnika, 1983. 